
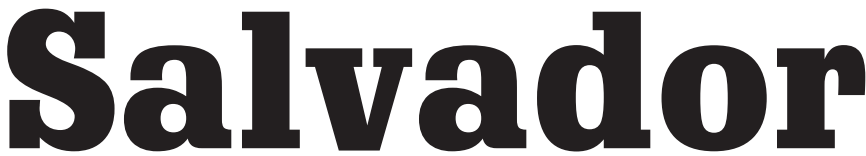

En el ambiente social es muy evidente la cultura del fraude intelectual, donde cualquier persona sin preparación académica asume obligaciones que no le competen. Esto lo que evidencia es el poco control estatal, debido a que estamos ante la cultura del fraude degenerado, en donde el individuo hasta puede comprar atribuciones de abogado o de médico sin que nadie controle ese tipo de prácticas.

Ramón D. Rivas

Director Museo Universitario de Antropología (MUA) de la UTEC

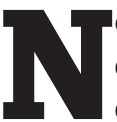

hay un estudio histórico en este país —comenzando desde la Colonia- en el que se aborde, en todas sus dimensiones, la evolución de las instituciones sociales. Los cronistas españoles, y el mismo obispo Cortez y Larraz Pedro Cortés y Larraz (1921) en su célebre descripción que hizo de esta parte de la entonces provincia de Guatemala y en el marco de su visita canónica, son los primeros referentes escritos que se acercan al estudio de la institucionalidad del control social y la legalidad y en cierta forma del poder del Estado. Luego, fueron los cronistas foráneos y los viajeros en retomar el tema en el siglo XIX. Pero no hay que olvidar que la visión que tiene el europeo de nosotros desde el descubrimiento es que somos individuos y sociedades con remanentes "primitivos" y atrasados frente a sociedades capitalistas del norte atlántico. La antropología social nace precisamente en este tipo de aventura. Una especie de visión de espionaje de mercadeo.

El punto es que, con el nacimiento del Estado salvadoreño a finales del siglo XIX, se inicia un proyecto de dominación particular basado principalmente en mecanismos coercitivos más que ideológicos, donde la fragilidad económica que producía el monocultivo del café no le permitía tener solvencia para
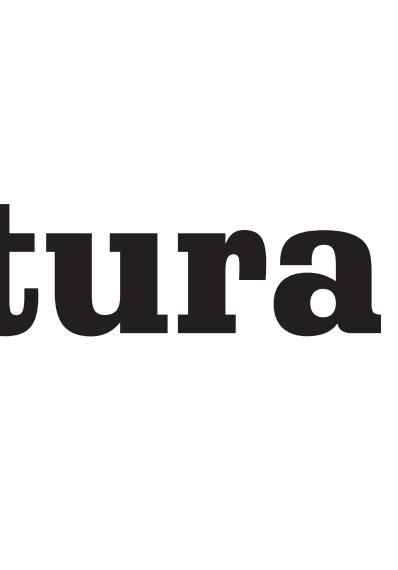

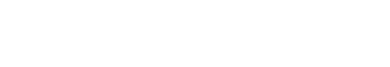


consolidar la institucionalidad del Estado. Es decir, no es que se niegue que no habían instituciones -tipo secretarías o ministerios-, la cuestión es que su alcance a escala nacional era limitado y estaba, más que todo, anclado en el centro y occidente del país. Es más, los monopolios y la cultura del fraude que venía desde la época colonial era un hecho en la clase dominante, lo que poco a poco se hizo cultura en todos los sectores sociales, salvo algunas excepciones. Con el surgimiento de la Guardia Nacional en 1912 y luego la Policía de Hacienda en 1932, ya en la época del general Martínez, vemos que se crea un ente paralelo al ejército nacional que defiende los intereses de los terratenientes y gamonales, donde la legislación nacional era omitida en prácticas de control político y económico. Esto se contrapone a lo que dice la teoría de Max Weber, en el sentido que el Estado es una institución que controla el poder. Pero en El Salvador nos encontramos con un ente militar paralelo al ejército nacional e incluso con más poder que este.

Las prácticas políticas electorales de ese momento estaban manipuladas e imperaba el fraude, con el fin de mantener a una elite política en el poder. Pero la pregunta es: ¿Será que el Estado es el que produce este tipo de prácticas o, más bien, reproduce lo que la familia como institución básica de la sociedad crea?

Vemos que en este país impera la cultura del fraude en todos los ámbitos. Un ejemplo es que los niños cometen fraude mintiendo, haciendo trampas en los juegos, falsificando firmas, copiando en la escuela. En los centros de trabajo no se es eficiente en las labores encomendadas y ni mucho menos se muestra creatividad. $\mathrm{Y}$ es que lo correcto en toda sociedad sana es que tanto los líderes como las instituciones que son dirigidas por ellos deben de ser medidas por la opinión pública con base en su rendimiento.

Precisamente por esa "cultura de la trampa" es que nosotros muchas veces no podemos competir con empresas extranjeras que traen una visión de rendimiento $y$ eficiencia laboral diferente. Pero esta cultura tiene raíces históricas que se mantienen en la mentalidad colectiva de la sociedad, las cuales no son tan fáciles de transformar. El "compadrazgo" como estructura de poder - para utilizar la terminología de Segundo Montes- y la práctica social de la violencia política son fenómenos que hasta hace poco se están abordando científicamente. Montes fue el pionero $-y$ ya no hay otros estudios al respectoque estudió con amplia biografía, la institución del compadrazgo desde

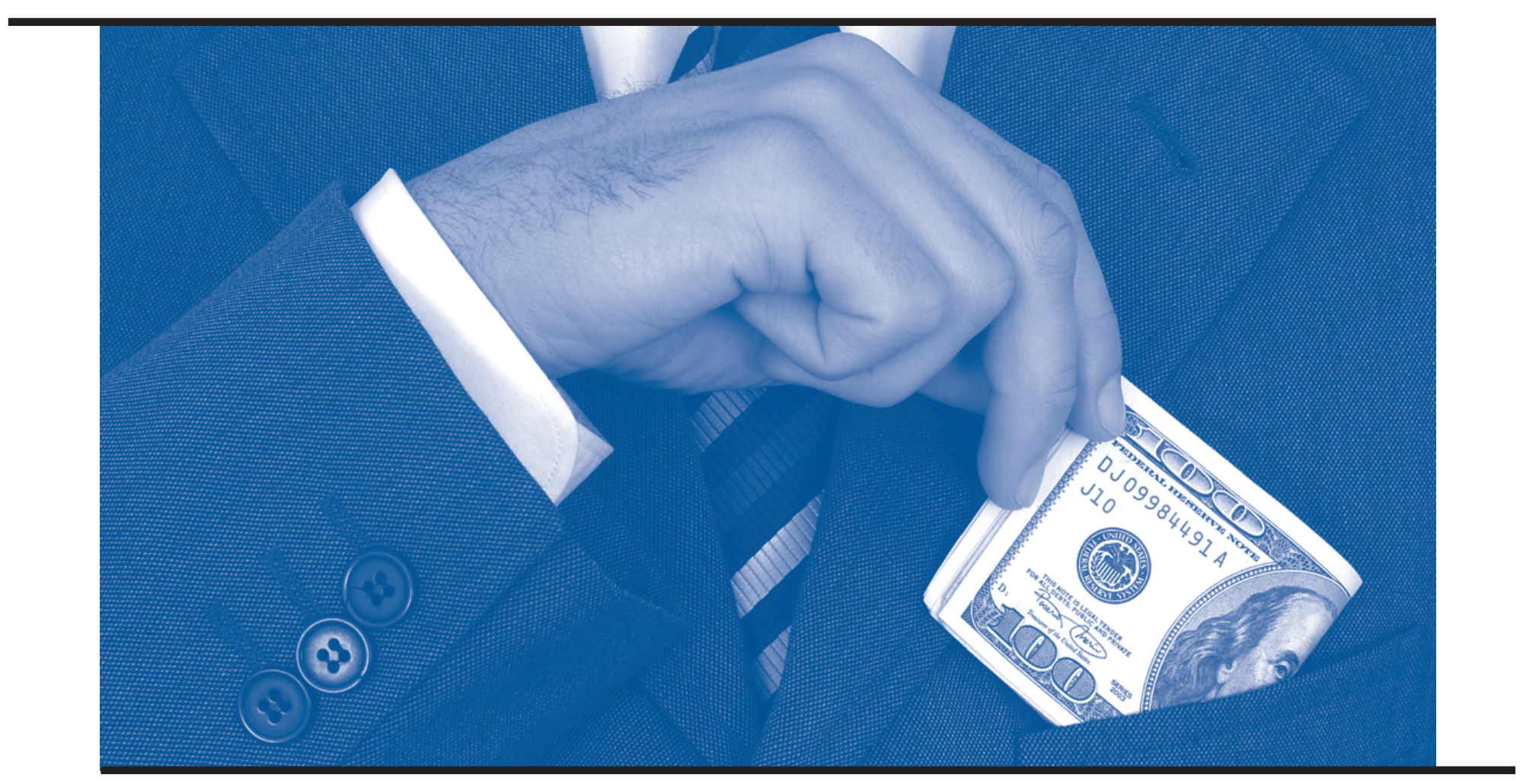


el ángulo histórico-antropológico, religioso y jurídico, tipificándolo en las distintas épocas y esclareciendo su papel en la sociedad precolombina, colonial y contemporánea. Para Montes, el compadrazgo juega en la vida social un papel de articulador, un factor de cohesión mediante el cual se alcanzan y conjugan diversas formas de poder, diversas instancias de familiaridad entre elementos de una misma clase social, y de relación entre individuos y familias de otras clases, estratos y estamentos. Los tipos de compadrazgo son múltiples y accionan horizontal y verticalmente, generando conductas, procedimientos y modos solidarios que inciden en el ejercicio del poder, condicionando el proceso por la vía de la costumbre religiosa y civil.

Sobre la cultura del fraude no hay estudios serios que nos ilustren. Es necesario realizarlos para entender la dimensión de este fenómeno. Claro está que es necesario cambiar la forma de relacionamiento y juego político de la sociedad, con el fin de consolidar el Estado de derecho y la asimilación de nuevos patrones de reracionamiento. El Estado ha tenido su control sobre las mentes y los cuerpos de los salvadoreños, ha sido exiguo ya que desde el punto de vista foucultiano, en los ámbitos institucional y discursivo, no ha sido coherente.

En el 2010 constatamos una sociedad salvadoreña rumbo a la modernización, pero con graves lastres de patrones culturales típicos de una sociedad "finquera", en donde la persona demuestra poca iniciativa por la prepotencia en el uso del poder. Observamos aún una sociedad patriarcal, una sociedad en donde "don Carleone" -el personaje mafioso de las novelas de de Mario Puzzo- se manifiesta en muchos aspectos de

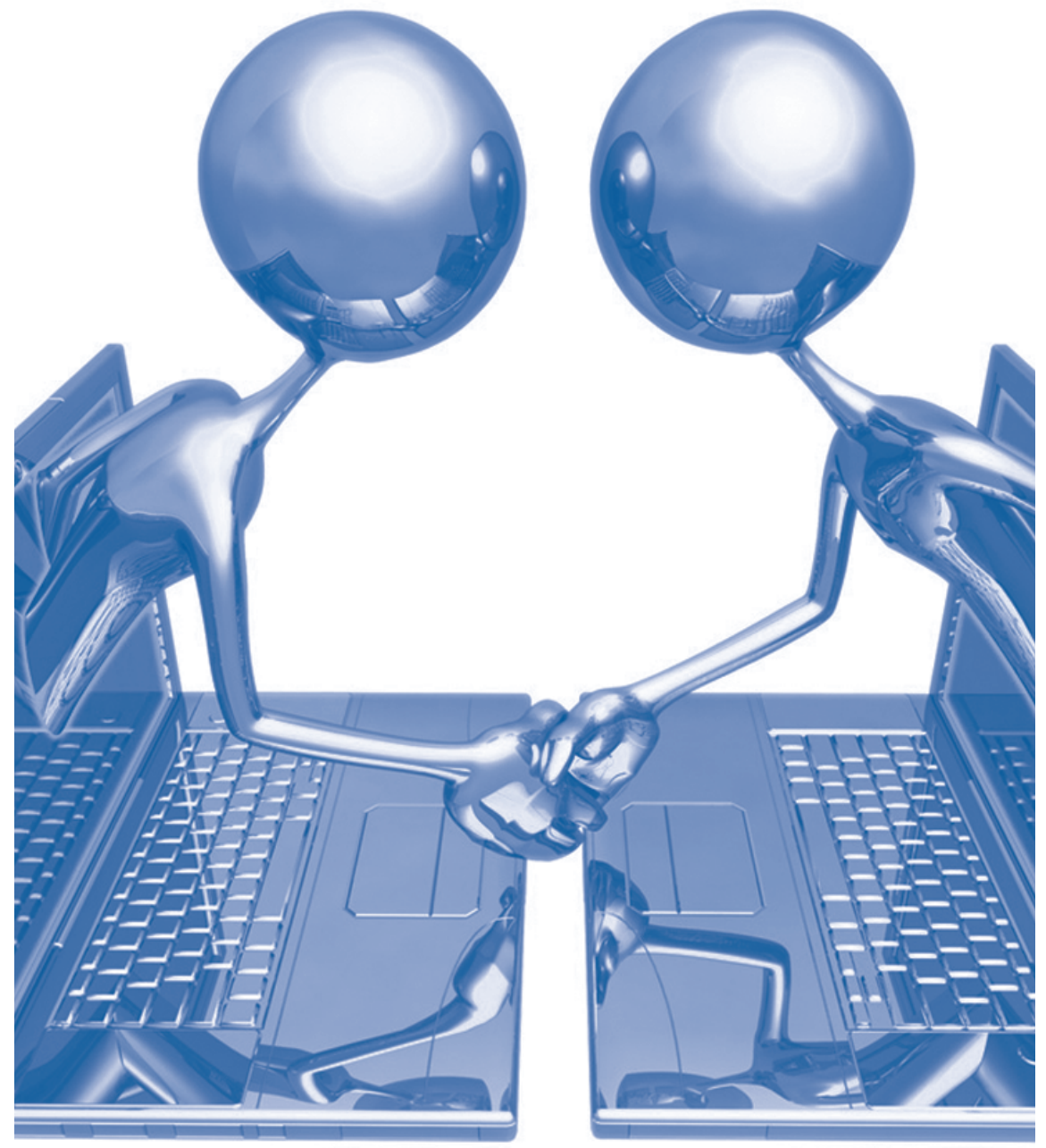

esta sociedad, con el fin de mantener su dominación. $Y$ nos referirnos a los aspectos sociales, económicos, culturales, políticos y hasta religiosos. Estamos ante estructuras de poder con importantes redes de control social y político y, por ende, del país. Pero esto también se ha ramificado, y por eso lo vemos también, a nivel micro, en los cantones, pueblos y ciudades. El compadrazgo es un hecho, y se manifiesta de diferentes y variadas maneras y en todos los ámbitos de la sociedad salvadoreña. Se acepta como un hecho cultural; y si queremos salir de esto hay que transformar esa cultura; y ello lleva tiempo, pero se puede.

Democratización de la sociedad

Por más que con la firma de los Acuerdos de Paz - llevada a cabo el 16 de enero del 1992 en el castillo de Chapultepec, México, entre las dos partes beligerantes, Gobierno y FMLN - se ha querido democratizar esta sociedad. Los mismos patrones de antaño mantienen las mismas prácticas políticas autoritarias y fraudulentas. Esperemos que este nuevo gobierno inicie "el cambio", 


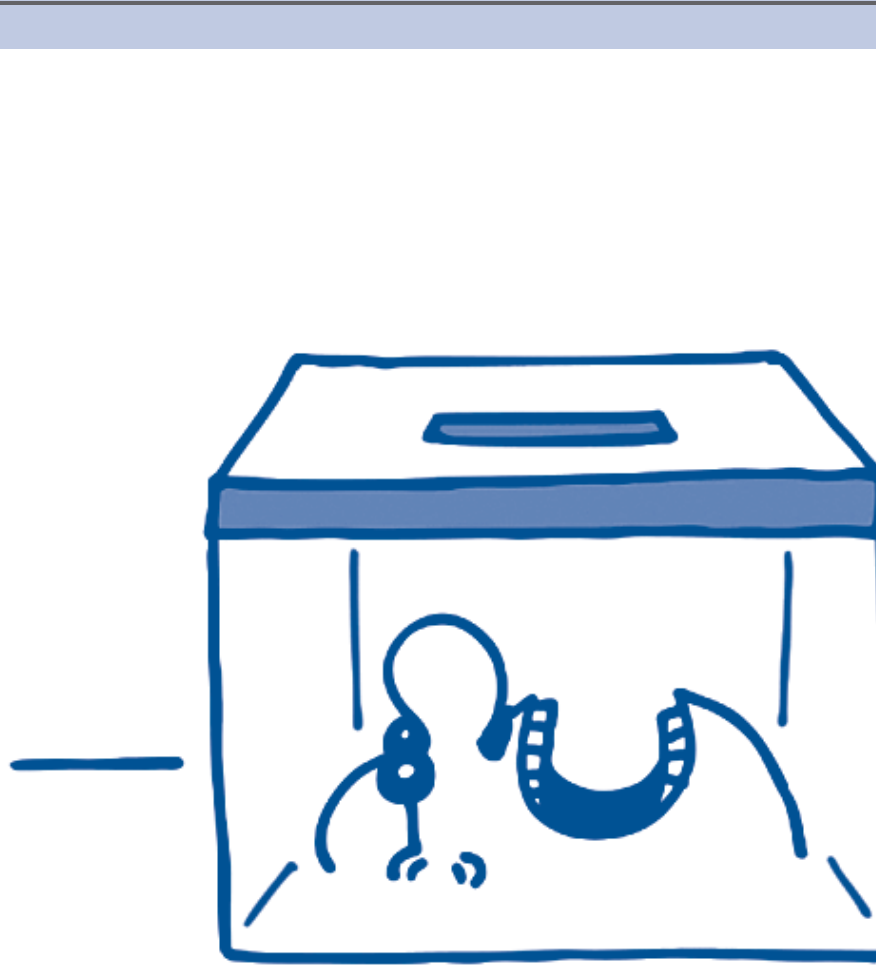

pero para que esto sea una realidad es necesario y urgente actuar con mano rígida y redimensionar que el fenómeno tiene raíces históricas.

En el ambiente social es muy evidente la cultura del fraude intelectual, donde cualquier persona sin preparación académica asume obligaciones que no le competen. Esto lo que evidencia es el poco control estatal y la poca criticidad ante falsos académicos, falsos líderes, y muchos de ellos guiados solo por el interés económico.

Estamos ante la cultura del fraude degenerado y vulgar en donde el individuo hasta puede comprar atribuciones de abogado, de médico e incluso hasta llegar a ser diputado o magistrado sin que nadie controle ese tipo de prácticas. Es más, a muchos les gusta atribuirse títulos académicos que no se han ganado.

El problema es que, ante este tipo hechos la sociedad, de la "cultura del fraude", se ha pasado a la "cultura de la desconfianza", lo que no permite crear tejido social ni mucho menos redes de solidaridad. Estamos ante una realidad social en donde todos desconfiamos de todos, de las personas y de las instituciones de cualquier tipo, sean políticas, religiosas o culturales. El mantener ese tipo de cultura imposibilita la concreción de un proyecto de comunidad nacional y la apertura política de las instituciones y del Estado. Si la gente, por ejemplo, desconfía de cómo se administra el Ministerio de Hacienda, ¿por qué este no pone en Internet sus estados de cuenta? ¿Por qué la Corte Suprema de Justicia no pone en Internet los casos resueltos?, ¿Por qué la Corte de Cuentas sigue en manos del mismo partido político? El Estado ya no es aquel Estado falsificador, corrupto, discriminatorio, sino que el mundo actual debe de llevarlo a su limpieza estructural y a la rendición de cuentas, donde la impunidad pronto quede exterminada. Es a esa sociedad a la que debemos aspirar, pero para ello debemos de comenzar desde ya. El conocimiento de la historia social y cultural del país es indispensable para desentrañar procesos y por ello la importancia de los estudios científicos y desde la academia.

\section{Las prácticas}

políticas electorales

de ese momento

estaban manipuladas

e imperaba el fraude, con el fin de mantener

a una elite política en el poder. Pero la pregunta es: ¿Será que el Estado es el que produce este tipo de prácticas o, más bien, reproduce lo que la familia como institución básica de la sociedad crea? 